\title{
ОПТИМИЗАЦИЯ РЕЖИМА ОСАЖДЕНИЯ БЕЛКОВ ПРИ ОПРЕДЕЛЕНИИ МОЛЕКУЛ СРЕДНЕЙ МАССЫ КАК МАРКЕРА ЭНДОГЕННОЙ ИНТОКСИКАЦИИ
}

Термин «интоксикационный синдром» был введен К.С. Симоняном в 1971 году и означал избыточное содержание в крови токсичных продуктов и биологически активных веществ [1]. В современном понимании синдром эндогенной интоксикации (СЭИ) относится к числу наиболее распространенных в клинической практике и наблюдается при разнообразных, этиологически и патогенетически различных состояниях [2-5]. СЭИ включает в себя проявления патологического состояния, возникающего в результате действия на организм токсических веществ эндогенного происхождения [6], и характеризуется интенсификацией катаболизма, нарушением функционирования механизмов естественной детоксикации, развитием депрессии иммунной системы [7]. СЭИ широко используется в качестве одного из основных критериев, определяющих тяжесть состояния больного и прогноз болезни.

Некоторые исследователи рассматривают эндогенную интоксикацию как этиологический фактор в контексте синдрома системного воспалительного ответа («systemic inflammatory response syndrome» - SIRS) [8]. Воспалительная peакция организма развивается согласно общим закономерностям в ответ на инфекцию, травму, тканевую деструкцию, гипоксию тканей, инфекционные процессы и, в том числе, интоксикацию. Эта реакция зачастую сопутствует СЭИ и является адаптационной функцией организма, направленной на уничтожение вызвавшего процесс агента и восстановление поврежденных систем.

Обобщая различные точки зрения относительно эндогенной интоксикации, можно сделать вывод, что в начале процесса эндотоксины поступают в кровь, лимфу, интерстициальную жидкость из патологического очага (воспаление, травмированные ткани, опухоли и т.д.). Если организм в состоянии элиминировать эти вещества, клинической симптоматики может и не возникнуть. При декомпенсации защитных и регуляторных систем - выделительной, де- токсикационной (микросомального окисления, конъюгации), мононуклеарно-макрофагальной - начинается накопление эндогенных токсинов в организме, способное привести к тяжелому состоянию, вплоть до летального исхода [4].

Для определения лечебной тактики и выбора оптимальной программы интенсивной терапии СЭИ необходимо обеспечить диагностику выраженности эндотоксикоза. Многокомпонентность факторов агрессии, которые лежат в основе эндотоксикоза, и индивидуальность адаптационных реакций организма конкретного пациента создают трудности для прямого мониторинга выраженности СЭИ по алгоритму «фактор - уровень интоксикации» или «фактор - стадия эндотоксикоза». Важное значение имеет функциональный фон организма, на котором развивается эндотоксикоз, например, состояние пораженного органа и связанной с ними функциональной системы детоксикации [9]. Попытка опереться в решении вышеописанных задач только на маркеры интоксикации недостаточно результативна, однако такое исследование, несомненно, дает информацию о первичном проявлении интоксикации, ориентирует в ее источниках и механизмах.

Существует множество классификаций эндотоксинов, в частности разделение на продукты жизнедеятельности патогенных микроорганизмов, не характерных для метаболизма человека $[10,11]$, чрезмерное накопление естественных метаболитов в сверхфизиологических концентрациях [12], в том числе продуктов катаболизма и протеолиза белков [13], а также различных медиаторов воспаления [14].

Многообразие современных лабораторных критериев, характеризующих тяжесть СЭИ, а также позволяющих определять динамику токсичности компонентов внутренней среды и ста-

() М.А. Барсукова, Л.С. Дмитриев, Е.Д. Якубенко, Е.В. Хомутов, 2021

(c) Университетская Клиника, 2021 
дию эндотоксикоза, не всегда доступны в широкой клинической практике по причине сложности и высокой стоимости исполнения. Поскольку тяжелое течение СЭИ в краткосрочной перспективе может привести к негативным последствиям, особо актуальным вопросом остается выбор достоверного, быстрого и недорогого критерия оценки тяжести данного синдрома.

В данном ключе часто используют общепринятый интегральный маркер метаболических нарушений - молекулы средней массы (MCM). На данный момент упоминание о МСМ в научной электронной библиотеке elibrary.ru превышает 100000 и сопряжено с изучением разнообразнейших патологических состояний и болезней, частью клинической картины которых является эндотоксикоз. В работах, рассматривающих накопление МСM, ссылаются на методики определения по Н.И. Габриэляну [15], а также на методически сходные модификации А.Н. Ковалевского [16] и М.Я. Малаховой [17]. Результаты определения МСМ представляют как отражение накопления пептидных, нуклеиновых и ароматических фракций веществ $[15,16]$ или же накопления веществ низкой и средней молекулярных масс катаболического и анаболического пулов с выраженной биологической активностью [17]. Динамика содержания МСМ в плазме крови является критерием эффективности проводимых мероприятий по детоксикации и применяемой терапии. При этом изменения концентрации других общепринятых маркеров СЭИ (мочевина, креатинин и др.) не всегда соответствуют динамике уровня МСМ, хоть и отражают особенности их метаболизма, транспорта или ретенции [13].

Анализ накопления МСМ - довольно оригинальный подход к мониторингу метаболиче- ских нарушений. Спектр поглощения плазмы крови каждого человека определяется количеством кислоторастворимых веществ (низкомолекулярных метаболитов) по величине поглощения света в ультрафиолетовой области спектра (230-300 нм). В клинической практике используют способы оценки уровня МСМ в биологических образцах, отвечающие требованиям, предъявляемым к скрининговым методам. При этом различия в некоторых методических приемах и использование трихлоруксусной кислоты (ТХУ) могут приводить к проблемам в интерпретации результатов. С целью повышения информативности данного диагностического маркера в работе представлено обоснование модификации общепринятого метода определения MCM.

\section{МАТЕРИАЛ И МЕТОДЫ}

Материалом для исследования послужила кровь 10 здоровых добровольцев в возрасте 2025 лет.

Содержание МСМ определяли спектрофотометрически на приборе Specord-200 (AnalytikJena, Германия) по общепринятым методикам [15, 17], а также в собственной вариации с использованием 10-процентной хлорной кислоты (ХK). Протокол проведения анализа представлен в таблице 1 . В супернатанте также измеряли концентрацию пептидов по методу Лоури [18].

\section{РЕЗУЛЬТАТЫ И ОБСУЖДЕНИЕ}

В основе общепринятых методических вариантов определения МСМ лежит принцип депротеинизации исследуемого биологического материала (сыворотка, плазма, эритроциты, моча) с помощью 10-процентной ТХУ с последующим определением величины поглощения (А) супер-

Ход определения МСM

Таблица 1.

\begin{tabular}{lcc}
\hline \multicolumn{1}{c}{ Реагент, мл } & \multicolumn{2}{c}{ Исследуемые пробы } \\
\cline { 2 - 3 } & $\begin{array}{l}\text { Биологический образец } \\
\text { (плазма или сыворотка) }\end{array}$ & Холостая проба \\
\hline Плазма/сыворотка & 1 & 1 \\
\hline Дистиллированная вода & - & 0,5 \\
\hline Осаждающий агент (10-процентная ТХУ или ХК) & 0,5 & 0,5 \\
\hline $\begin{array}{l}\text { Пробы тщательно перемешать, инкубировать 20' при комнатной температуре, затем центрифугировать } \\
\text { при 8000 об/мин 30'. }\end{array}$ & 0,5 & 4,5 \\
\hline Супернатант & 4,5 & 0 \\
\hline Дистиллированная вода & & 0 \\
\hline
\end{tabular}

Пробы перемешать, измерить в диапазоне 200-300 нм против дистиллированной воды [15] и против холостой пробы [16, 17]. 
натанта при определенных длинах волн (238, 240, 254, 280 нм) относительно дистиллированной воды [15] или «холостой пробы» (табл. 1.) $[16,17]$. Исходя из принципа проведения данного анализа, под молекулами средней массы подразумеваются кислотоустойчивые неидентифицированные вещества различной химической природы (пептиды, нуклеотиды, продукты углеводного, липидного, азотистого обмена), поглощающие свет в ультрафиолетовом диапазоне (200-300 нм) с молекулярной массой от 300 до 5000 Д.

На рисунке 1 представлены средние значения спектров поглощения МСМ здоровых добровольцев по общепринятым методам, а также спектр поглощения «холостой пробы» против дистиллированной воды.

На рисунке изображены спектры поглощения - распределение величины абсорбции (А) всех находящихся в растворе веществ в зависимости от длины волны поглощаемого света. Уровни МСМ определяют на 4 длинах волн и выражают в Е (в единицах оптической плотности, нормированных на оптический путь - см-1), peферентные показатели: МСМ- $\lambda 238$ нм - 0,56$0,76 \mathrm{E}$; MCM- $\lambda 254$ нм - 0,18-0,24 E; MCM- $\lambda 260$ нм - 0,16-0,28 Е; МСM - 2280 нм - 0,18-0,30 Е [19]. Данные референтные значения основаны на варианте метода определения МСМ по Н.И. Габриэляну [15] и не в полной мере совпадают с та- ковыми по М.Я. Малаховой [17]: «нормальная спектрограмма плазмы крови при длинах волн 238 и 242 нм имеет сопряжение с осью абсцисс (нулевые значения экстинкции)» [9].

Как видно из рисунка 1, экстинкции растворов сходны в диапазоне 260-300 нм для обоих используемых методов определения. В диапазоне 220-260 нм результаты определения МСМ значительно разнятся в зависимости от варианта исполнения анализа.

Этап пробоподготовки в общепринятых методах регистрации МСМ одинаков, существенное различие наблюдается на этапе спектрофотометрирования. В первом варианте (рис.1., график 1) регистрацию оптического поглощения депротеинизированного с помощью 10процентной ТХУ супернатанта в опытной кювете проводят против контрольной кюветы, содержащей дистиллированную воду. Соответственно, спектр поглощения исследуемого образца, согласно закону аддитивности светопоглощения [20], будет состоять из суммарного поглощения МСМ и ТХУ, которая, как органическая кислота, имеет высокий коэффициент экстинкции на длинах волн от 200 до 240 нм (рис. 1., график 3). Оптическая плотность «холостой

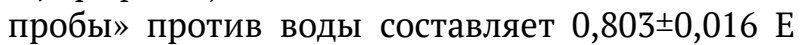
при 238 нм и 0,614ะ0,014 Е при 240 нм. Это означает, что максимум поглощения в диапазоне 220-260 нм по методике [15] соответствует пику

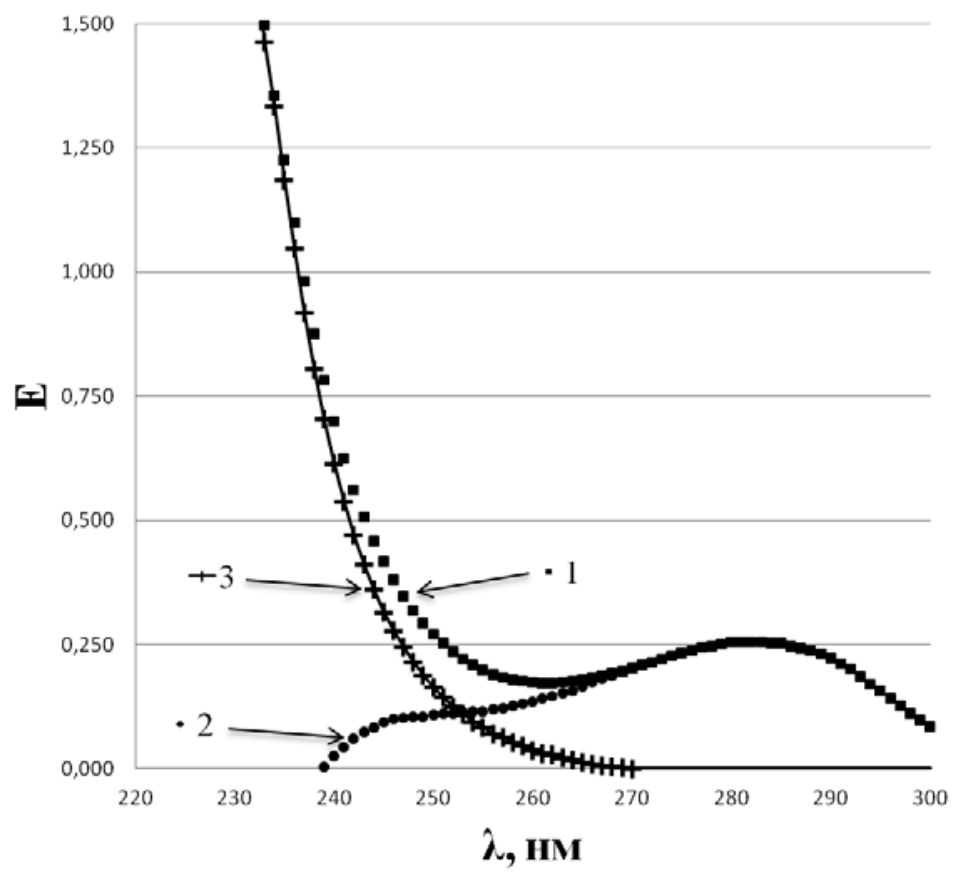

Рис. 1. Спектры поглощения МСМ сыворотки крови здоровых добровольцев по методике Н.И. Габриэляна (график 1), в вариации методики по А.Н. Ковалевскому и М.Я. Малаховой (график 2) и «холостой пробы» против дистиллированной воды (график 3). 
поглощения ТХУ в исследуемом растворе. Поскольку величина оптической плотности ТХУ при 238 нм приходится на диапазон референтных значений МСМ, любые неточности в приготовлении и хранении раствора могут оказывать существенное влияние на величину МСМ. Также стоит отметить, что в данном варианте измерения МСМ регистрируемая величина поглощения исследуемого раствора при 238 нм находится на уровне верхней границы оптимального рабочего диапазона спектрофотометрического оборудования, что означает более высокую относительную погрешность измерения [20].

Во втором варианте (рис.1., график 2) измерение оптического поглощения опытной пробы проводят против контрольной кюветы с «холостой пробой»- раствором, содержащим ТХУ в той же пропорции, что и опытная проба. Принцип фотометрии подразумевает получение результата, состоящего из разницы поглощения опытного и контрольного образца. Поскольку «холостая проба» (рис.1., график 3) имеет значительную величину поглощения, в модификации [17] участок спектра 220-260 нм систематически занижается.

При проведении анализа МСМ определение абсорбции депротеинизированных биологических образцов при разных длинах волн проводится с целью условного выделения группы веществ по максимуму поглощения. Использова- ние ТХУ в качестве осадителя крупномолекулярных белков дает ложные результаты, завышая [15] или занижая [17] реальную величину поглощения в диапазоне 220-260 нм, где максимум поглощения имеют различные вещества, имеющие в составе связи N-H [21] и представляющие диагностическую ценность при оценке СЭИ: пептиды, ароматические аминокислоты, мочевая кислота, мочевина.

Таким образом, для оценки реального поглощения в этом диапазоне и сохранения оригинального подхода к выявлению МСМ необходимо использовать осаждающий агент, не поглощающий свет в ультрафиолетовом диапазоне.

Реакции осаждения белков весьма разнообразны, в лабораторной практике в качестве осаждающих агентов зачастую используют органические и минеральные кислоты, а также органические растворители [22]. Органические кислоты и растворители вызывают дегидратацию и денатурацию белковых молекул по сложному механизму, включающему как непосредственное воздействие на водородные связи, так и блокирование полярных групп. Такой подход дает высокую эффективность депротеинизации (осаждаются все белковые и пептидные молекулы с массой выше 5 кДа), но имеет ряд недостатков. Как было описано ранее, ТХУ прямо влияет на величину поглощения в УФ диапазоне. Методы депротеинизации органическими раствори-

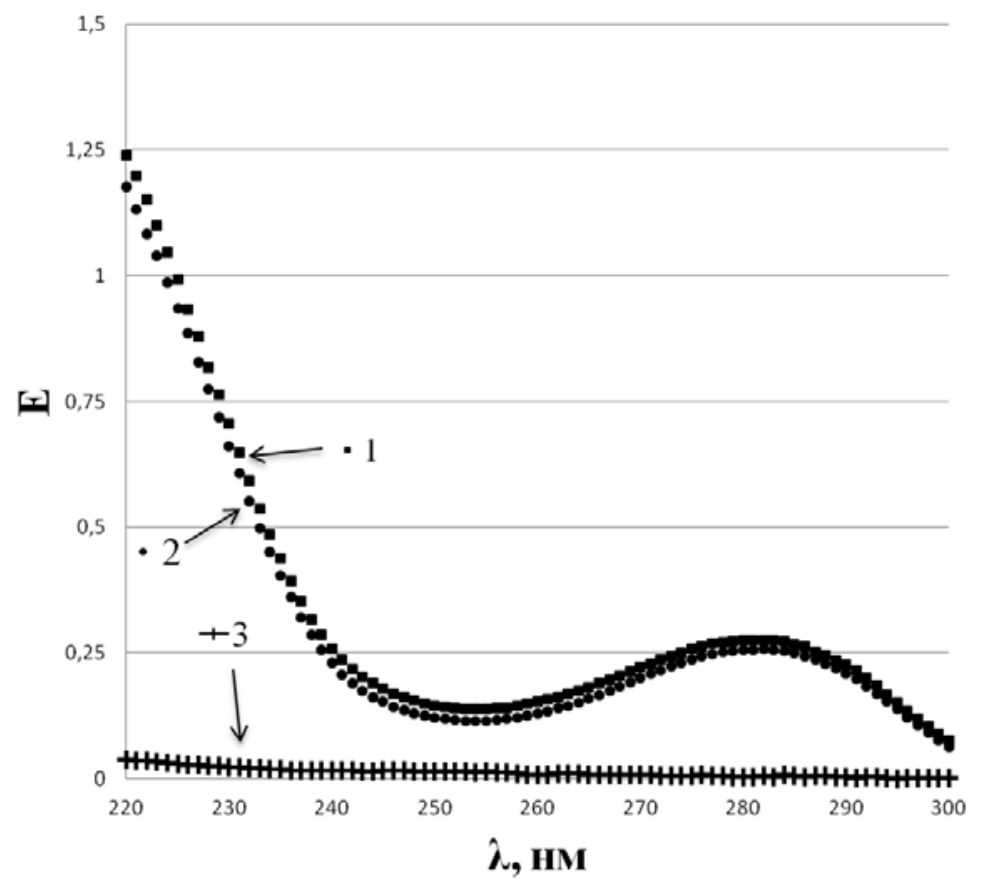

Рис. 2. Спектры поглощения МСМ сыворотки крови здоровых добровольцев против кюветы с дистиллированной водой (график 1), против кюветы с «холостой пробой» (график 2) и «холостой пробы» (график 3). 


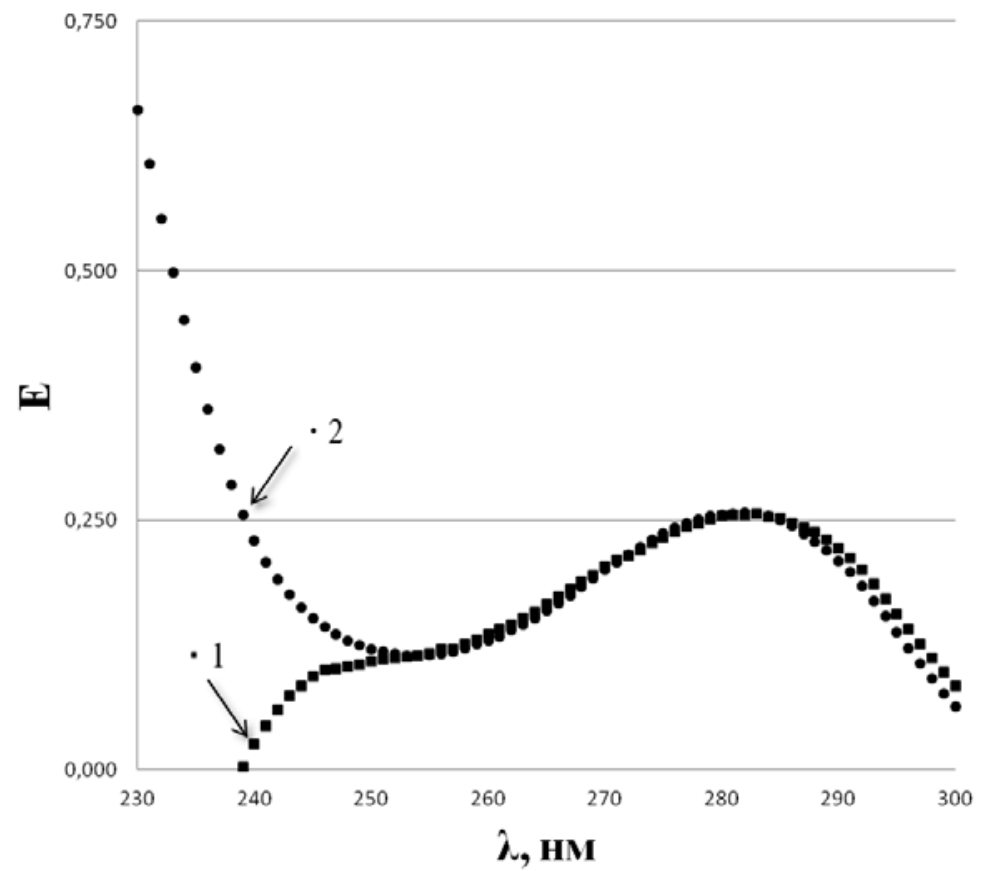

Рис. 3. Спектры поглощения МСМ сыворотки крови здоровых добровольцев против кюветы с «холостой пробой» с использованием ТХУ (график 1) и ХК (график 2).

телями обычно включают несколько этапов, методически более сложны и дорогостоящи в использовании. Выбранная нами XK- широко применяемый осаждающий агент [23], относящийся к классу минеральных кислот. Механизм осаждения минеральными кислотами проще: он заключается в разрыве гидратной оболочки белковых молекул, что означает меньшую степень депротеинизации.

На рисунке 2 представлены средние значения спектров поглощения МСМ контрольной группы, полученные с использованием 10процентной XK.

Использование ХK в качестве осаждающего агента позволяет регистрировать реальную величину поглощения исследуемого раствора во всем диапазоне длин волн, поскольку присутствующая в растворе ХК имеет в нем незначительное поглощение (рис.2., график 3).

На рисунке 3 можно отметить значительные различия поглощения в диапазоне 230-250 нм и практически полное совпадение на остальном участке. Это свидетельствует о совпадении небелкового состава исследуемых проб с использованием ТХУ и ХК. В отношении пептидной фракции (диапазон 220-260 нм), опираясь на величины абсорбции (Е), достоверно оценить различия осаждающих агентов не представляется возможным из-за влияния ТХУ. Поскольку низкомолекулярные кислоторастворимые пептиды напрямую связаны с тяжестью прогноза для пациента, являясь участниками воспаления (ЦИК, белки острой фазы и цитокины), продуктами протеолиза [24], а также непосредственно выступая в роли «связывающих токсины пептидов» [25], то, с нашей точки зрения, необходимым является определение концентрации пептидов по методу Лоури. Этот шаг позволит количественно определить содержание молекул, имеющих в своем составе пептидную группу. Концентрации пептидов в супернатанте представлены в таблице 2 .

\section{З А К ЛЮЧ Е Н ИЕ}

При определении МСМ предложенным нами вариантом, с использованием ХК вместо ТХУ, в супернатанте обнаруживается в 2 раза больше соединений, вступающих в цветную реакцию для пептидной связи. Эти результаты можно объяснить различием механизмов депротеинизации ТХУ и ХК, причем последняя эффективна в качестве осаждающего агента основных крупномолекулярных белков плазмы (альбумин и глобулины), за исключением ХК-растворимых низкомолекулярных гликопротеинов и щелочных белков.

Осаждение ХК уже используется как инструмент пробоподготовки для анализа различных малых молекул и гликопротеинов [26]. Это традиционный метод выделения мукопротеинов сыворотки - гликозилированных сывороточных белков, которые, как и МСM, рассматривают в 
Концентрация пептидов после осаждения крупномолекулярных белков

\begin{tabular}{ccc}
\hline & С белка после ТХУ, мг/мл & С белка после ХК, мг/мл \\
\hline $\mathrm{M}^{ \pm} \sigma$ & $0,562 \pm 0,205$ & $1,218 \pm 0,080$ * \\
\hline
\end{tabular}

* - различия достоверны между вариантами осадителя (критерий Манна-Уитни р=0,003).

качестве потенциальных биомаркеров тяжести и прогрессирования некоторых патологических состояний и заболеваний.

Качественный состав фракции ХК-растворимых белков активно исследуется, уже известно, что в нее входят некоторые маркеры воспаления и белки острой фазы (оросомукоид, гаптоглобин, гемопексин, альфа-1-анти-трипсин) [27]. На текущий момент ХК-растворимые белки наиболее изучены при злокачественных заболеваниях [28, 29, 30]. В качестве потенциальных биомаркеров прогрессирования заболевания их связывают с диабетом [31], сердечнососудистыми [32] и инфекционными заболеваниями [33].

Таким образом, в предложенном нами варианте исследования МСМ пептидно-белковая фракция состоит из низкомолекулярных пептидов (ТХУ-растворимых) и ХК-растворимых белков. Изучение динамики накопления этих веществ предоставляет клинически значимую информацию, необходимую для раннего распознавания и мониторинга тяжести широкого спектра патологических состояний, в том числе СЭИ.

Различия в содержании низкомолекулярных пептидов и ХК-растворимых пептидов на данный момент слабо изучены, при этом они могут иметь большое значение в медицинской лабораторной практике. Оригинальная концепция определения МСM, дополненная фракцией кислоторастворимых маркеров воспаления, вполне подходит на роль быстрого и информативного интегрального показателя тяжести СЭИ.

\section{В Ы В О Д Ы}

1. Использование в качестве осаждающего раствора 10-процентной трихлоруксусной кислоты сопряжено с неадекватными результатами оценки спектров в диапазоне 200-260 нм.

2. Раствор хлорной кислоты в концентрации 10 \% может быть использован для осаждения белков вместо 10-процентной трихлоруксусной кислоты, не внося существенных недостатков в спектральное определение содержания молекул средней массы.

3. При осаждении хлорной кислотой возможно также определить пептиды и гликопептиды, представляющие диагностическую ценность при многих патологических состояниях, в том числе и СЭИ.

4. Для более точной оценки концентрации белков и пептидов рекомендуется измерять в супернатанте их концентрацию по методу Лоури.

\section{М.А. Барсукова, Л.С. Дмитриев, Е.Д. Якубенко, Е.В. Хомутов}

ГОО ВПО «Донецкий национальный медицинский университет имени М. Горького», Донецк

\section{ОПТИМИЗАЦИЯ РЕЖИМА ОСАЖДЕНИЯ БЕЛКОВ ПРИ ОПРЕДЕЛЕНИИ МОЛЕКУЛ СРЕДНЕЙ МАССЫ КАК МАРКЕРА ЭНДОГЕННОЙ ИНТОКСИКАЦИИ}

Синдром эндогенной интоксикации (СЭИ) часто встречается в клинической практике, его маркеры используются в качестве критериев, определяющих тяжесть состояния больного и прогноз болезни. Многообразие современных лабораторных критериев, характеризующих тяжесть СЭИ, а также позволяющих определять динамику токсичности компонентов внутренней среды, не всегда доступны по причине сложности и высокой стоимости исполнения. В данном ключе часто используют общепринятый интегральный маркер метаболических нарушений - молекулы средней массы (МСM). Различия в некоторых методических приемах и использование трихлоруксусной кислоты в качестве осадителя дают ложные результаты, искажая реальную величину поглощения в диапазоне максимума оптического поглощения веществ, имеющих в составе связи N-H и обладающих диагностической ценностью при оценке СЭИ. В работе представлено обоснование модификации общепринятого метода определения МСМ путем изменения осаждающего агента на хлорную кислоту. В предложенном нами варианте исследования МСМ предоставляется возможным оценивать содержание как низкомолекулярных пептидов, так и гликопептидов. Изучение динамики их накопления дает клинически значимую информацию, необходимую для раннего распознавания и мониторинга тяжести разнообразных патологических состояний, в том числе СЭИ.

Ключевые слова: эндогенная интоксикация, молекулы средней массы, кислоторастворимые пептиды, гликопептиды. 


\section{M.A. Barsukova, L.S. Dmitriev, E.D. Yakubenko, E.V. Khomutov}

\section{SEI HPE «M. Gorky Donetsk National Medical University», Donetsk}

\section{OPTIMIZATION OF THE PROTEIN DEPOSITION REGIME IN DETERMINING AVERAGE MASS MOLECULES AS A MARKER OF ENDOGENOUS INTOXICATION}

Endogenous intoxication syndrome (SEI) is often found in clinical practice; its markers are used as criteria that determine the severity of the patient's condition and the prognosis of the disease. The variety of modern laboratory criteria characterizing the severity of SEI, as well as allowing to determine the dynamics of toxicity of the components of the internal environment, are not always available due to the complexity and high cost of execution. For this purpose, a generally accepted integral marker of metabolic disorders is often used - medium mass molecules (MSM). Differences in some methodological techniques and the use of trichloroacetic acid as a precipitant give false results, distorting the real value of absorption in the range where the maximum of optical absorption of substances that have an $\mathrm{N}-\mathrm{H}$ bond in the composition and which have diagnostic value in the evaluation of EIS is located. The paper presents the rationale for modifying the generally accepted method for determining MSM by changing the precipitating agent to perchloric acid. In our proposed version of the study of MSM, it is possible to assess the content of both low molecular weight peptides and glycopeptides. The study of the dynamics of their accumulation provides clinically significant information necessary for early recognition and monitoring of the severity of a wide range of pathological conditions, including SEI.

Key words: endogenous intoxication, molecules of average weight, acid-soluble peptides, glycopeptides.

\section{ЛИТЕРАТУРА}

1. Афанасьева А.Н., Одинцова И.Н., Удут В.В. Синдромы эндогенной интоксикации и системного воспалительного ответа: общность и различия. Анестезиология и реаниматология. $2007 ; 4: 67-71$.

2. Парахонский А.П. Патогенез клинических проявлений синдрома эндогенной интоксикации. Заметки ученого. 2015; 1 (1): 188-195.

3. Терещенко О.А., Боташев А.А., Помещик Ю.В., Петросян Э.А., Сергиенко В.И. Синдром эндогенной интоксикации и системной воспалительной реакции при желчном перитоните, осложненном абдоминальным сепсисом. Вестник экспериментальной и клинической хирургии. $2012 ; 5$ (4): 722-726. doi 10. 18499/2070-478X2012-5-4-722-726

4. Уракова Т.Ю., Лысенкова Н.С. Эндогенная интоксикация и адаптационные возможности у пациентов с ожирением. Международный журнал прикладных и фундаментальных исследований. 2009; 5: 39-45.

5. Власов А.П., Болотских В.А., Шейранов Н.С., Болушев П.О., Глушков В.М. и др. Оксидативный стресс и активизация фосфолипаз - факторы прогрессирования эндогенной интоксикации. Современные проблемы науки и образования. 2019; $4: 3$.

6. Оболенский С.В., Малахова М.Я. Лабораторная диагностика интоксикаций в практике интенсивной терапии. СПб: Издание института усовершенствования врачей; 1991. 17.

7. Шмойлов Д.К., Каримов И.З., Одинец Т.Н. Патогенетическая роль эндогенной интоксикации. Лабораторна діагностика. 2012; 2: 65-70.

8. Chakraborty R.K., Burns B. Systemic Inflammatory Response Syndrome. StatPearls Publishing (2020). URL: https://www.ncbi.nlm.nih.gov/books/NBK547669/

9. Карпищенко А.И., ред. Медицинская лабораторная диагностика. Программы и алгоритмы. Руководство для врачей. 3-е изд. М.: ГЭОТАР-Медиа; 2014. 696.

10. David S.A., Sil D. Development of Small-Molecule Endotoxin Sequestering Agents. Sub-cellularbiochemistry. 2010; 53: 255-283. doi 10.1007/978-90-481-9078-2 12

11. Гагуа А.К., Стрельников А.И., Вальков К.С., Иваненков И.М., Воробьёв П.Ю. Возможности использования летучих жирных кислот в диагностике гнойного холангита и определении вида микрофлоры у больных механической желтухой. Вестник ИвГМА. 2015; 3: 44-47.

12. Келина Н.Ю., Безручко Н.В., Рубцов Г.К. Биохимические проявления эндотоксикоза: методические аспекты изучения и оценки, прогностическая значимость (аналитический обзор). Вестник ТюмГУ. 2012; 6: 143147.

13. Юрьева Э.А., Сухорукое В.С., Царегородцев А.Д. и др.

\section{REFERENCES}

1. Afanas'eva A.N., Odintsova I.N., Udut V.V. Sindromy endogennoi intoksikatsii i sistemnogo vospalitel'nogo otveta: obshchnost' i razlichiya. Anesteziologiya i reanimatologiya. 2007; 4: 67-71 (in Russian).

2. Parakhonskii A.P. Patogenez klinicheskikh proyavlenii sindroma endogennoi intoksikatsii. Zametki uchenogo. 2015; 1 (1): 188-195 (in Russian).

3. Tereshchenko O.A., Botashev A.A., Pomeshchik Yu.V., Petrosyan E.A., Sergienko V.I. Sindrom endogennoi intoksikatsii i sistemnoi vospalitel'noi reaktsii pri zhelchnom peritonite, oslozhnennom abdominal'nym sepsisom. Vestnik eksperimental'noi i klinicheskoi khirurgii. 2012; 5 (4): 722-726 (in Russian). doi 10. 18499/2070-478X-2012-5-4722-726

4. Urakova T.Yu., Lysenkova N.S. Endogennaya intoksikatsiya $i$ adaptatsionnye vozmozhnosti u patsientov s ozhireniem. Mezhdunarodnyi zhurnal prikladnykh i fundamental'nykh issledovanii. 2009; 5: 39-45 (in Russian).

5. Vlasov A.P., Bolotskikh V.A., Sheiranov N.S., Bolushev P.O., Glushkov V.M. i dr. Oksidativnyi stress i aktivizatsiya fosfolipaz - faktory progressirovaniya endogennoi intoksikatsii. Sovremennye problemy nauki i obrazovaniya. 2019; 4: 3 (in Russian).

6. Obolenskii C.B., Malakhova M.Ya. Laboratornaya diagnostika intoksikatsii $\mathrm{v}$ praktike intensivnoi terapii. SPb: Izdanie instituta usovershenstvovaniya vrachei; 1991. 17 (in Russian).

7. Shmoilov D.K., Karimov I.Z., Odinets T.N. Patogeneticheskaya rol' endogennoi intoksikatsii. Laboratorna diagnostika. 2012; 2: 65-70 (in Russian).

8. Chakraborty R.K., Burns B. Systemic Inflammatory Response Syndrome. StatPearls Publishing (2020). URL: https://www.ncbi.nlm.nih.gov/books/NBK547669/

9. Karpishchenko A.I., red. Meditsinskaya laboratornaya diagnostika. Programmy i algoritmy. Rukovodstvo dlya vrachei. 3-e izd. M.: GEOTAR-Media; 2014. 696 (in Russian).

10. David S.A., Sil D. Development of Small-Molecule Endotoxin Sequestering Agents. Sub-cellularbiochemistry. 2010; 53: 255-283. doi 10.1007/978-90-481-9078-2 12

11. Gagua A.K., Strel'nikov A.I., Val'kov K.S., Ivanenkov I.M., Vorob'ev P.Yu. Vozmozhnosti ispol'zovaniya letuchikh zhirnykh kislot v diagnostike gnoinogo kholangita i opredelenii vida mikroflory $\mathrm{u}$ bol'nykh mekhanicheskoi zheltukhoi. Vestnik IvGMA. 2015; 3: 44-47 (in Russian).

12. Kelina N.Yu., Bezruchko N.V., Rubtsov G.K. Biokhimicheskie proyavleniya endotoksikoza: metodicheskie aspekty izucheniya i otsenki, prognosticheskaya znachimost' (analiticheskii obzor). Vestnik TyumGU. 2012; 6: 143-147 (in Russian). 
Изменение белковых молекул при эндогенной интоксикации организма как фактор риска хронических обменных болезней. Молекулярная медицина. 2013; 3 : 45-52.

14. Кузнецов П.Л., Борзунов В.М. Синдром эндогенной интоксикации в патогенезе вирусного гепатита. Экспериментальная и клиническая гастроэнтерология. 2013; 4: 44-50.

15. Габриэлян Н.И., Левицкий Э.Р., Дмитриев А.А. Скрининговый метод определения средних молекул в биологических жидкостях: Методические рекомендации. М: Издательство Московского университета; 1985. 26.

16. Ковалевский А.Н., Нифянтьев О.Е. Замечания по скрининговому методу определения молекул средней массы. Лабораторное дело. 1989; 5: 35-39.

17. Малахова М.Я. Формирование биохимического понятия «субстрат эндогенной интоксикации»: Тезисы Международного симпозиума «Эндогенные интоксикации». СПб. ; 1994: 38

18. Малахова М.Я. Метод регистрации эндогенной интоксикации. Пособие для врачей. СПб; 1995. 33.

19. Мантула АА., Проценко Т.В., Якубенко Е.Д. Особенности нарушений биохимического гомеостаза придерматологической патологии у больных вирусными гепатитами. Університетська клініка. 2010; 6 (1-2): 33-36.

20. Алемасова А.С. Аналитическая химия. Донецк: Ноулидж; 2010. 417.

21. Antosiewicz, J.M., Shugar, D. UV-Vis spectroscopy of tyrosine side-groups in studies of protein structure. Part 1: basic principles and properties of tyrosine chromophore. Biophysical Reviews. 2016; 8: 151-161. doi: 10. 1007/ s12551-016-0198-6

22. Ганеева Л.А. и др. Биохимия. Практикум: Учебное пособие по курсу «Медицинская биохимия». Казань: ИСБ; 2015. 176.

23. Galluzzi L., Rudqvist N.P. Methods in Enzymology. Vol. 629. San Diego: Elsevier Academic Press; 2019. 552

24. Сидельникова В.И., Черницкий А.Е., Рецкий М.И. Эндогенная интоксикация и воспаление: последовательность реакций и информативность маркеров. Сельскохозяйственная биология. 2015; 50 (2): 152-161.

25. Эфендиев А.М., Гидаятова 3.Г., Дадашова А.Р., Гаджиев А.Г. Значение эндогенных антимикробных пептидов в формировании иммунного статуса у больных с хроническим вирусным гепатитом С. Трудный пациент. 2017;15 (4-5): 28-31.

26. Makszin L., Kustán P., Szirmay B., Páger C., Mező E. et al. Microchip gel electrophoretic analysis of perchloric acid-soluble serum proteins in systemic inflammatory disorders. Electrophoresis. 2019; 40 (3): 447-454. doi: 10. 1002/ elps. 201800378

27. Allison A. Structure and Function of Plasma Proteins. Boston: Springer; 1974. 318. doi: 10.1007/978-1-46842676-2

28. Ma R., Xu H., Wu J. et al. Identification of serum proteins and multivariate models for diagnosis and therapeutic monitoring of lung cancer. Oncotarget. 2017; 8 (12): 18901-18913. doi: 10.18632/oncotarget. 14782

29. Malaker S.A., Ferracane M.J., Depontieu F.R. et al. Identification and Characterization of Complex Glycosylated Peptides Presented by the MHC Class II Processing Pathway in Melanoma. Journal of proteome research. 2017; 16 (1): 228-237. doi: 10.1021/acs.jproteome.6b00496

30. Shu Q., Li M., Shu L. et al. Large-scale Identification of Nlinked Intact Glycopeptides in Human Serum using HILIC Enrichment and Spectral Library Search. Molecular \& cellular proteomics. 2020; 19 (4): 672-689. doi: $10.1074 / \mathrm{mcp}$. RA119.001791

31. Basso D., Valerio A., Seraglia R. et al. Putative pancreatic cancer-associated diabetogenic factor: 2030 MW peptide. Pancreas. 2002; 24 (1): 8-14. doi: 10.1097/00006676200201000-00002

32. Rubin R.B., Merchant M. A rapid protein profiling system that speeds study of cancer and other diseases. American clinical laboratory. 2000; 19 (8): 28-29.

33. Dosekova E., Filip J., Bertok T., Both P., Kasak P., Tkac J. Nanotechnology in Glycomics: Applications in Diagnostics, Therapy, Imaging, and Separation Processes. Medicinal research reviews. 2017; 37 (3): 514-626. doi: 10.1002/ med.21420
13. Yur'eva E.A., Sukhorukoe V.S., Tsaregorodtsev A.D. i dr. Izmenenie belkovykh molekul pri endogennoi intoksikatsii organizma kak faktor riska khronicheskikh obmennykh boleznei. Molekulyarnaya meditsina. 2013; 3 : 45-52 (in Russian).

14. Kuznetsov P.L., Borzunov V.M. Sindrom endogennoi intoksikatsii $\mathrm{V}$ patogeneze virusnogo gepatita. Eksperimental'naya i klinicheskaya gastroenterologiya. 2013; 4: 44-50 (in Russian).

15. Gabrielyan N.I., Levitskii E.R., Dmitriev A.A. Skriningovyi metod opredeleniya srednikh molekul v biologicheskikh zhidkostyakh: Metodicheskie rekomendatsii. M Izdatel'stvo Moskovskogo universiteta; 1985. 26 (in Russian).

16. Kovalevskii A.N., Nifyant'ev O.E. Zamechaniya po skriningovomu metodu opredeleniya molekul srednei massy. Laboratornoe delo. 1989; 5: 35-39.

17. Malakhova M.Ya. Formirovanie biokhimicheskogo ponyatiya «substrat endogennoi intoksikatsii»: Tezisy Mezhdunarodnogo simpoziuma «Endogennye intoksikatsii». SPb. ; 1994: 38 (in Russian).

18. Malakhova M.Ya. Metod registratsii endogennoi intoksikatsii. Posobie dlya vrachei. SPb; 1995. 33 (in Russian).

19. Mantula AA., Protsenko T.V., Yakubenko E.D. Osobennosti narushenii biokhimicheskogo gomeostaza pridermatologicheskoi patologii u bol'nykh virusnymi gepatitami. Universitets'ka klinika. 2010; 6 (1-2): 33-36 (in Russian).

20. Alemasova A.S. Analiticheskaya khimiya. Donetsk: Noulidzh; 2010. 417 (in Russian).

21. Antosiewicz, J.M., Shugar, D. UV-Vis spectroscopy of tyrosine side-groups in studies of protein structure. Part 1: basic principles and properties of tyrosine chromophore. Biophysical Reviews. 2016; 8: 151-161. doi: 10. 1007/ s12551-016-0198-6

22. Ganeeva L.A. i dr. Biokhimiya. Praktikum: Uchebnoe posobie po kursu «Meditsinskaya biokhimiya». Kazan': ISB; 2015. 176 (in Russian).

23. Galluzzi L., Rudqvist N.P. Methods in Enzymology. Vol. 629. San Diego: Elsevier Academic Press; 2019. 552.

24. Sidel'nikova V.I., Chernitskii A.E., Retskii M.I. Endogennaya intoksikatsiya i vospalenie: posledovatel'nost' reaktsii i informativnost' markerov. Sel'skokhozyaistvennaya biologiya. 2015; 50 (2): 152-161 (in Russian).

25. Efendiev A.M., Gidayatova Z.G., Dadashova A.R., Gadzhiev A.G. Znachenie endogennykh antimikrobnykh peptidov $v$ formirovanii immunnogo statusa $u$ bol'nykh $s$ khronicheskim virusnym gepatitom S. Trudnyi patsient. 2017;15 (4-5): 28-31 (in Russian)

26. Makszin L., Kustán P., Szirmay B., Páger C., Mező E. et al. Microchip gel electrophoretic analysis of perchloric acid-soluble serum proteins in systemic inflammatory disorders. Electrophoresis. 2019; 40 (3): 447-454. doi: 10. 1002/ elps. 201800378

27. Allison A. Structure and Function of Plasma Proteins. Boston: Springer; 1974. 318. doi: 10.1007/978-1-46842676-2672

28. Ma R., Xu H., Wu J. et al. Identification of serum proteins and multivariate models for diagnosis and therapeutic monitoring of lung cancer. Oncotarget. 2017; 8 (12): 18901-18913. doi: 10.18632/oncotarget. 14782

29. Malaker S.A., Ferracane M.J., Depontieu F.R. et al. Identification and Characterization of Complex Glycosylated Peptides Presented by the MHC Class II Processing Pathway in Melanoma. Journal of proteome research. 2017; 16 (1): 228-237. doi: 10.1021/acs.jproteome.6b00496

30. Shu O., Li M., Shu L. et al. Large-scale Identification of Nlinked Intact Glycopeptides in Human Serum using HILIC Enrichment and Spectral Library Search. Molecular \& cellular proteomics. 2020; 19 (4): 672-689. doi: 10.1074/mcp. RA119.001791

31. Basso D., Valerio A., Seraglia R. et al. Putative pancreatic cancer-associated diabetogenic factor: 2030 MW peptide. Pancreas. 2002; 24 (1): 8-14. doi: 10.1097/00006676200201000-00002

32. Rubin R.B., Merchant M. A rapid protein profiling system that speeds study of cancer and other diseases. American clinical laboratory. 2000; 19 (8): 28-29.

33. Dosekova E., Filip J., Bertok T., Both P., Kasak P., Tkac J. Nanotechnology in Glycomics: Applications in Diagnostics, Therapy, Imaging, and Separation Processes. Medicinal research reviews. 2017; 37 (3): 514-626. doi: 10.1002/ med. 21420 